\title{
Amine-Manganese Complex as an Efficient Catalyst for Polyurethane Syntheses
}

\author{
Shin-ichi InOUe, Yasuharu NAGAI, and Hiroshi OKAMOTO \\ Department of Applied Chemistry, Aichi Institute of Technology, 1247 Yachigusa, Yakusa-cho, \\ Toyota 470-0392, Japan
}

(Received November 8, 2001; Accepted February 19, 2002)

\begin{abstract}
KEY WORDS Hexamethylene Diisocyanate / Diethylene Glycol / Manganese(II) Acethylaceto-
\end{abstract} nate / Triethylenediamine / Polyaddition / Polyurethane /

The polyurethane industry has progressed rapidly, and reactions of polyols and isocyanates are wellknown technological processes. The chemical structure of polyurethane is diverse, and as physical properties are discovered, the wide use of polyurethane is spreading accordingly. But there exists a problem: discoloration by air and light. In general, aliphatic isocyanate is used to resolve this problem. However, the reaction rate of aliphatic isocyanates on preparations of polyurethane is very slow compared with aromatic isocyanates. Therefore, tertiary amines ${ }^{1-5}$ and tin compounds, ${ }^{6-10}$ having excellent catalytic activity, are used mainly as catalysts for polyurethane formation. In particular, dibutyltin dilaurate (DBTDL) has been used. However, tin is toxic to human beings. Accordingly, a new catalyst or catalytic system is necessary to replace this catalyst. Recently, late transition metal complexes such as metal- $\beta$-diketone complexes $\left(\mathrm{Mt}(\mathrm{acac})_{n}\right)$ are being researched with great interest. ${ }^{1-13}$ For example, $\mathrm{Fe}(\mathrm{acac})_{3}$ and $\mathrm{Cu}(\mathrm{acac})_{2}$ complexes are used for the reaction between hexamethylene diisocyante (HDI) and alcohols. ${ }^{14,15}$ Although there is sufficiently the catalytic activity for only $\mathrm{Mt}(\mathrm{acac})_{n}$ complexes, the increase of the catalytic activity is expected by the cocatalyst. The co-catalyst plays important roles in many reactions. On urethane formation reaction, triphenyl bismuth (TPB)-hexafluoroacetylacetonato ( $\mathrm{f}_{6} \mathrm{acac}$ ) catalytic system shows high catalytic activity and the existence of the co-catalyst such as $\mathrm{f}_{6}$ acac is important to the reaction. ${ }^{16}$

In the present paper, the activities of $\mathrm{Mt}(\mathrm{acac})_{n}$ and tertiary amine-Mt(acac $)_{n}$ catalyst as new group catalytic system are described. The data clearly show that instead of DBTDL, the tertiary amine-Mt(acac $)_{n}$ can be used for catalyst of the reaction between HDI and alcohol.

\section{EXPERIMENTAL}

\section{Materials}

HDI and diethylene glycol (DEG) (Nacalai Tesque Inc.) were used immediately after distillation under reduced pressure. Manganese(II) $\left(\mathrm{Mn}(\mathrm{acac})_{2}\right)$, and iron(III) acethylacetonates $\left(\mathrm{Fe}(\mathrm{acac})_{3}\right)$ (Nacalai Tesque Inc.), cobalt (II) $\left(\mathrm{Co}(\mathrm{acac})_{2}\right)$, nickel (II) $\left(\mathrm{Ni}(\mathrm{acac})_{2}\right)$, copper (II) acethylacetonates $\left(\mathrm{Cu}(\mathrm{acac})_{2}\right)$, and dibutyltin dilaurate (DBTDL) (Tokyo Kasei Kogyo Co., Ltd.) were used as received. Triethylenediamine (TEDA), $N, N, N^{\prime}, N^{\prime \prime}, N^{\prime \prime}$-pentamethyldiethylenetriamine (DT), $N, N, N^{\prime}, N^{\prime}$-tetramethylethylenediamine (TE), bis(2-dimethylaminoethyl) ether (ETS), $N, N^{\prime}, N^{\prime}$ trimethylaminoethylpiperazine (NP) were delivered by Tosoh Co., Ltd. Toluene and $N, N$-dimethylformamide (DMF) (Nacalai Tesque Inc.) were dehydrated over a molecular sieve $(4 \AA)$ at room temperature for about $24 \mathrm{~h}$ before use. Di- $n$-butylamine and bromo cresol green (Nacalai Tesque Inc.) were used as received.

\section{Reaction between HDI and DEG Catalyzed by Metal-} $\beta$-Diketone

The reaction was performed under an argon atmosphere in a $200 \mathrm{~mL}$ three-necked glass vessel. In a typical experiment, $0.0897 \mathrm{~g}(0.31 \mathrm{mmol})$ of $\mathrm{Mn}(\mathrm{acac})_{2}$, $0.0348 \mathrm{~g}(0.31 \mathrm{mmol})$ of TEDA, $1.040 \mathrm{~g}(6.20 \mathrm{mmol})$ of HDI and $15 \mathrm{~mL}$ of DMF were placed in a $20 \mathrm{~mL}$ Schlenk tube. A $0.660 \mathrm{~g}(6.20 \mathrm{mmol})$ of DEG and $65 \mathrm{~mL}$ of DMF were placed in a $200 \mathrm{~mL}$ three-necked glass vessel.

The TEDA-metal complex with HDI in DMF solution and DEG-DMF solution were stirred at the desired reaction temperature (for example: $30^{\circ} \mathrm{C}$ ) for 30 min., and the catalyst and HDI in DMF solution 
Table II. Polyaddition reaction catalyzed by the TEDA-Mt(acac $)_{n}$ complex between HDI and DEG ${ }^{\text {a }}$

\begin{tabular}{|c|c|c|}
\hline Catalyst & $k / \mathrm{L} \mathrm{mol}^{-1} \mathrm{~h}^{-1}$ & $K_{\mathrm{C}} \times 10^{4} / \mathrm{L}^{2} \mathrm{eq}^{-1} \mathrm{~mol}^{-1} \mathrm{~h}^{-1}$ \\
\hline none & 0.2 & - \\
\hline TEDA-Mn(acac $)_{2}$ & 102.2 & 2.8 \\
\hline TEDA-Fe(acac) $)_{3}$ & 49.3 & 1.3 \\
\hline TEDA-Co(acac $)_{2}$ & 14.4 & 0.4 \\
\hline TEDA-Ni(acac $)_{2}$ & 1.6 & - \\
\hline $\mathrm{TEDA}-\mathrm{Cu}(\mathrm{acac})_{2}$ & 3.5 & - \\
\hline
\end{tabular}

${ }^{\mathrm{a}}\left[\mathrm{Mt}(\mathrm{acac})_{n}\right]=0.0036 \mathrm{~mol} \mathrm{~L}^{-1},[\mathrm{HDI}]=[\mathrm{DEG}]=0.073 \mathrm{~mol} \mathrm{~L}^{-1}$, Temp. $=30^{\circ} \mathrm{C}$, Solvent $=$ $\mathrm{DMF}, \mathrm{TEDA} / \mathrm{Mt}=1 \mathrm{in}$ mol ratio.

Table I. Polyaddition reaction catalyzed by the $\operatorname{Mt}(\text { acac })_{n}$ complex without amines between HDI and $\mathrm{DEG}^{\mathrm{a}}$

\begin{tabular}{lcc}
\hline Catalyst & $k / \mathrm{L} \mathrm{mol}^{-1} \mathrm{~h}^{-1}$ & $K_{\mathrm{C}} \times 10^{4} / \mathrm{L}^{2} \mathrm{eq}^{-1} \mathrm{~mol}^{-1} \mathrm{~h}^{-1}$ \\
\hline none & 0.2 & - \\
DBTDL & 139.6 & 3.8 \\
$\mathrm{Mn}(\mathrm{acac})_{2}$ & 52.3 & 1.4 \\
$\mathrm{Fe}(\mathrm{acac})_{3}$ & 24.4 & 0.7 \\
$\mathrm{Co}(\mathrm{acac})_{2}$ & 5.8 & 0.2 \\
$\mathrm{Ni}(\mathrm{acac})_{2}$ & 1.7 & - \\
$\mathrm{Cu}(\mathrm{acac})_{2}$ & 1.9 & - \\
\hline${ }^{\mathrm{a}}[$ Catalyst $]=0.0036 \mathrm{~mol} \mathrm{~L}-1,[\mathrm{HDI}]=[\mathrm{DEG}]=0.073 \mathrm{~mol}$ \\
$\mathrm{~L}^{-1}$, Temp. $=30^{\circ}$, solvent $=\mathrm{DMF}$.
\end{tabular}

were added to the DEG-DMF solution. After the reaction started, aliquots $(8 \mathrm{~mL})$ were removed from the reaction solution at regular time intervals $(5$ or $10 \mathrm{~min}$ ) and predetermined excess di- $n$-dibutylamine solution (typically $10 \mathrm{~mL}$ of $1.0 \mathrm{~mol} \mathrm{~L}^{-1}$ ) was added. Unreacted amine was back-titrated using standard hydrochloric acid (typically $0.5 \mathrm{~mol} \mathrm{~L}^{-1}$ ) to a bromo cresol green end-point. The rate constant was calculated from simple second-order kinetics.

\section{Characterization}

Molecular weight and molecular weight distribution were determined by GPC using a Tosoh GPC-8020 in tetrahydrofuran (THF) at $40^{\circ} \mathrm{C}$ calibrated as standard polystyrenes. IR spectra (in $\mathrm{KBr}$ pellets) were recorded on a JASCO FT/IR-5300 spectrometer.

\section{RESULTS AND DISCUSSION}

Table I shows the reactions catalyzed by $\operatorname{Mt}(\mathrm{acac})_{n}$ between HDI and DEG at $30^{\circ} \mathrm{C}$ in DMF. From the theory of Farkas ${ }^{3}$ and Hostettler, ${ }^{4}$ the catalytic constant $\left(K_{\mathrm{c}}\right)$ was calculated as eq 1 ,

$$
k=k_{0}+K_{\mathrm{c}}[\text { catalyst }]^{n}
$$

and rate constants $\left(k_{0}\right.$ : uncatalyzed system and $k$ : catalyzed system) were calculated from simple secondorder kinetics. The reaction between HDI and DEG did not proceed without a catalyst, but when the $\mathrm{Mt}(\mathrm{acac})_{n}$ complex was used as catalyst, the reaction between HDI and DEG proceeded speedily. The
$\mathrm{Mn}(\mathrm{acac})_{2}$ catalyst reached a high conversion $(>80 \%)$ after $60 \mathrm{~min}$ and attained total conversion after 120 min, whereas $\mathrm{Fe}(\mathrm{acac})_{3}$ showed $85 \%$ conversion after $120 \mathrm{~min} \mathrm{Fe}(\mathrm{acac})_{3}$ catalyst has good to excellent catalytic activity for the reaction between HDI and ethanol. ${ }^{14,15}$ However, under our experimental conditions, the catalytic activity of $\mathrm{Mn}(\mathrm{acac})_{2}$ was even higher, and the catalytic activity of $\mathrm{Mn}(\mathrm{acac})_{2}$ was about twice that of $\mathrm{Fe}(\mathrm{acac})_{3}$. Although the catalytic activity of $\mathrm{Mn}(\mathrm{acac})_{2}$ was very high, it was lower (about $1 / 3$ ) than the activity of DBTDL. The catalytic activity of $\mathrm{Mt}(\mathrm{acac})_{n}$ was lower than that of DBTDL because HDI was inert coordinated to $\mathrm{Mt}(\mathrm{acac})_{n}$. Using metal together with amine, further catalytic activity is expected. Thus, we examined the effects of added amine toward polyaddition reaction catalyzed by $\mathrm{Mt}(\mathrm{acac})_{n}$ complexes.

Table II summarizes the effects of added TEDA to $\mathrm{Mt}(\mathrm{acac})_{n}$ complex. Although the reaction catalyzed by $\mathrm{Mt}(\mathrm{acac})_{n}$ proceeded, the reaction catalyzed by TEDA did not proceed and the co-catalyst such as TEDA was inactive. The order of catalytic activity was TEDA$\mathrm{Mn}(\mathrm{acac})_{2}>$ TEDA-Fe(acac $)_{3}>$ TEDA-Co $(\mathrm{acac})_{2}>$ TEDA-Ni(acac $)_{2}>$ TEDA-Cu(acac $)_{2}$, the same as in the case of reaction without TEDA. When TEDA$\mathrm{Mn}(\mathrm{acac})_{2}$ complex was used as catalyst, catalytic activity was two times more active than $\mathrm{Mn}(\mathrm{acac})_{2}$. The catalytic activity of $\mathrm{Mn}(\mathrm{acac})_{2}$ is improved, when TEDA is used as co-catalyst. The GPC elution curve of polyurethane obtained with TEDA-Mn(acac $)_{2}$ complex showed a mulch modal, and number average molecular weight $\left(M_{\mathrm{n}}\right)$ of the resulting polyurethane was 2700 (polyurethane conversion was 95\%). This GPC elution curve was the same as that of DBTDL. The activity of this catalytic system using TEDA and $\mathrm{Mn}(\mathrm{acac})_{2}$ was comparable to that of DBTDL, and this catalytic system will be replacing DBTDL catalytic system.

At the next step of the investigation, the effects of other amines such as DT, TE, ETS, and NP were examined. Table III summarizes the effects of added these amines to $\mathrm{Mn}(\mathrm{acac})_{2}$ complex. These amines were inactive on the reaction. $\mathrm{Mn}(\mathrm{acac})_{2}$ activated with TEDA showed fairly good catalytic activity (conversion was 
Table III. Polyaddition reaction catalyzed by the amine-Mn(acac $)_{2}$ complex between HDI and DEG ${ }^{\text {a }}$

\begin{tabular}{|c|c|c|}
\hline Catalyst & $k / \mathrm{L} \mathrm{mol}^{-1} \mathrm{~h}^{-1}$ & $K_{\mathrm{C}} \times 10^{4} / \mathrm{L}^{2} \mathrm{eq}^{-1} \mathrm{~mol}^{-1} \mathrm{~h}^{-1}$ \\
\hline none & 0.2 & - \\
\hline TEDA-Mn(acac $)_{2}$ & 102.2 & 2.8 \\
\hline DT-Mn(acac $)_{2}$ & 40.6 & 1.1 \\
\hline $\mathrm{TE}-\mathrm{Mn}(\mathrm{acac})_{2}$ & 39.9 & 1.1 \\
\hline ETS-Mn(acac) $)_{2}$ & 88.2 & 2.4 \\
\hline NP-Mn(acac $)_{2}$ & 44.5 & 1.2 \\
\hline
\end{tabular}

${ }^{\mathrm{a}}\left[\mathrm{Mn}(\mathrm{acac})_{2}\right]=0.0036 \mathrm{~mol} \mathrm{~L}^{-1},[\mathrm{HDI}]=[\mathrm{DEG}]=0.073 \mathrm{~mol} \mathrm{~L}^{-1}$, Temp. $=30^{\circ} \mathrm{C}$, Solvent $=$ $\mathrm{DMF}$, amine/ $\mathrm{Mn}=1$ in mol ratio.

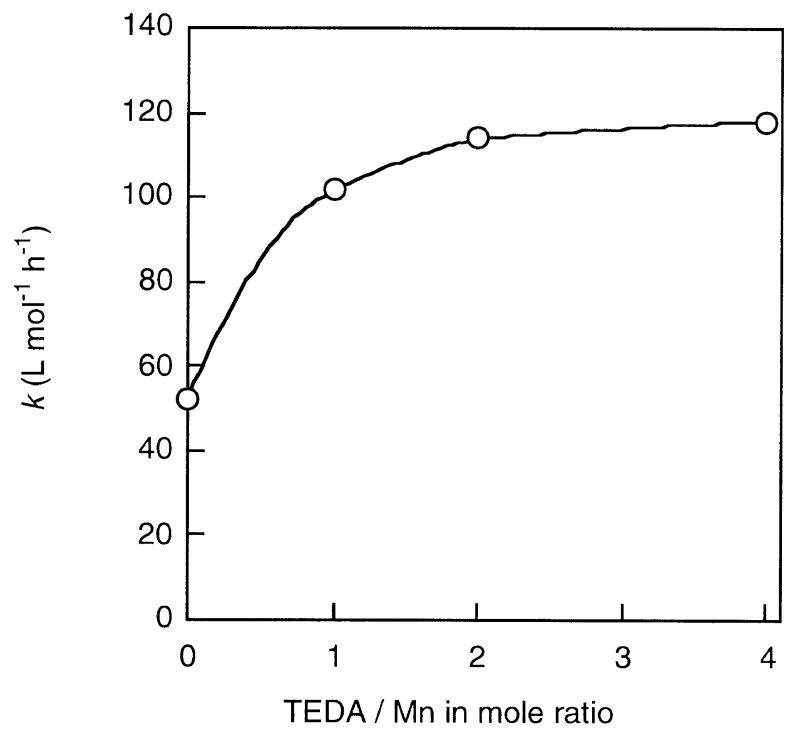

Figure 1. Effects of adding TEDA $([\mathrm{HDI}]=[\mathrm{DEG}]=$ $\left.0.073 \mathrm{~mol} \mathrm{~L}^{-1},[\mathrm{Mn}(\mathrm{acac}) 2]=0.0036 \mathrm{~mol} \mathrm{~L}^{-1}\right)$.

95\%), while other amines exhibited somewhat low catalytic activity (conversion was $75 \%$ ).

The existence of a co-catalyst such as TEDA is important to this reaction. Thus, we examined the effects of the TEDA/Mn(acac $)_{2}$ molar ratio. Molar ratios of TEDA to $\mathrm{Mn}(\mathrm{acac})_{2}$ changed from 1:1 to 2:1 and 4:1, as depicted in Figure 1. The activity of the catalyst was dependent on the TEDA/Mn(acac) $)_{2}$ molar ratio. With increasing TEDA molar, the rate constant $(k)$ increased. $k, 102$ when [TEDA]/[Mn(acac $\left.)_{2}\right]$ was 1 , increased with this ratio, and was saturated around 120.

The reaction catalyzed by TEDA-Mn(acac $)_{2}$ between HDI and DEG was kinetically investigated. Figure 2 shows the time-reciprocal of isocyanate concentration plots in the temperature range $0-30^{\circ} \mathrm{C}$. The reciprocal of isocyanate concentration linearly increased with reaction time. From an Arrhenious plot of $k$ estimated from the plots in Figure 2, the overall activation energy $\left(E_{\mathrm{a}}\right)$ of the reaction between HDI and DEG was $58.4 \mathrm{~kJ} \mathrm{~mol}^{-1}$. In the case of DBTDL, $E_{\mathrm{a}}$ was 71.4 $\mathrm{kJ} \mathrm{mol}^{-1}$. $E_{\mathrm{a}}$ of TEDA-Mn(acac $)_{2}$ complex is somewhat lower than that of DBTDL.

Figure 3 presents the relationship between $k$ and catalyst concentration ([TEDA-Mn(acac $\left.\left.)_{2}\right]\right)$. For wide

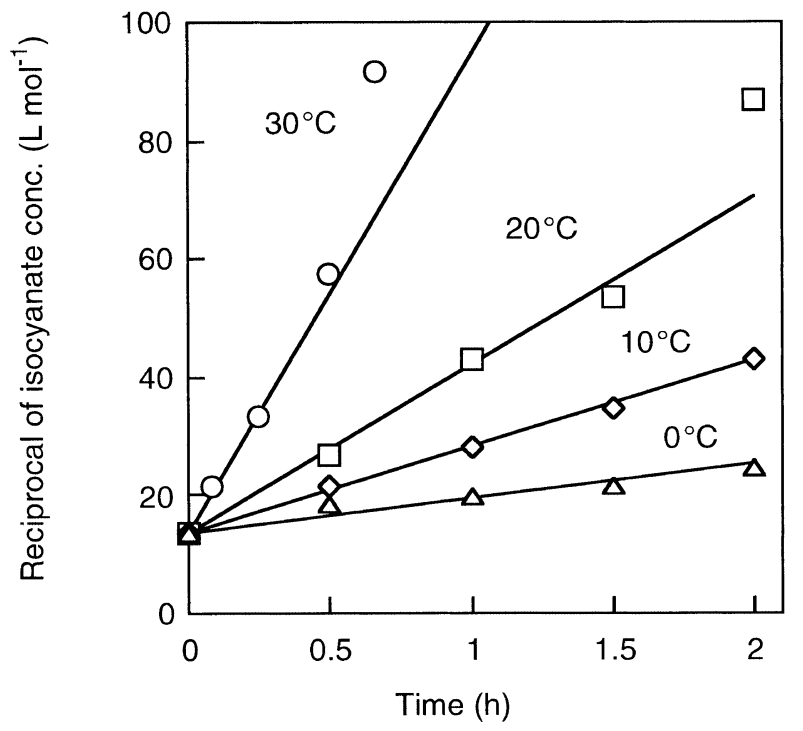

Figure 2. Time-reciprocal of isocyanate concentration plots in the reaction between HDI and DEG in DMF at different temperatures $\left([\mathrm{HDI}]=[\mathrm{DEG}]=0.073 \mathrm{~mol} \mathrm{~L}^{-1},\left[\mathrm{Mn}(\mathrm{acac})_{2}\right]=0.0036\right.$ $\mathrm{mol} \mathrm{L}{ }^{-1}, \mathrm{TEDA} / \mathrm{Mn}=1$ in mol ratio).

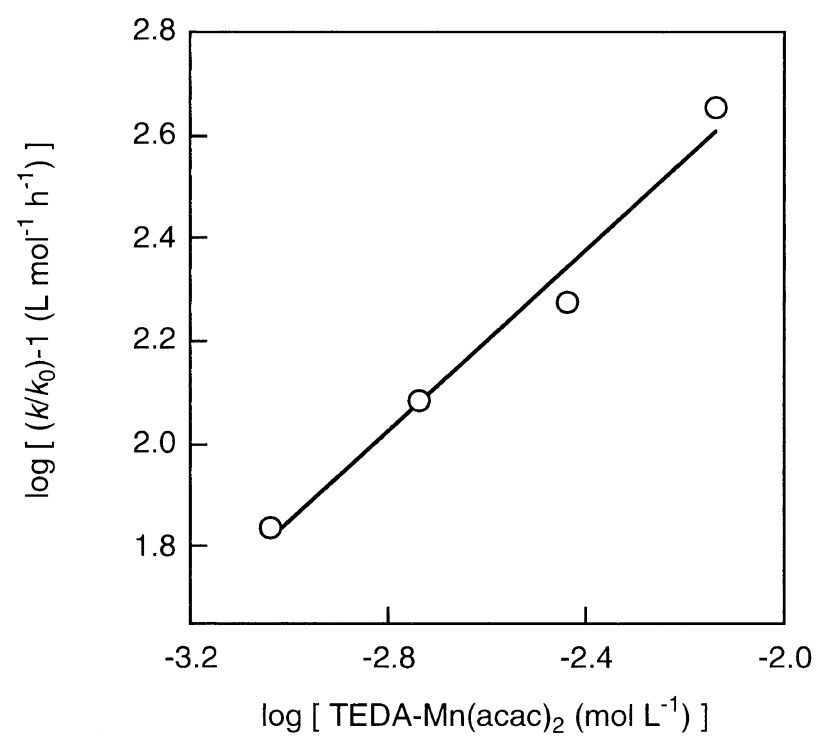

Figure 3. Dependence of $k$ on TEDA/Mn(acac) $2(1 / 1)$ catalyst concentration $([\mathrm{HDI}]=[\mathrm{DEG}]=0.073 \mathrm{~mol} \mathrm{~L}-1, \mathrm{TEDA} / \mathrm{Mn}=1$ in mol ratio, Temp. $=30^{\circ} \mathrm{C}$, Solvent $\left.=\mathrm{DMF}\right)$.

concentration range, the logarithmic expression was,

$$
\left.\log \left(k / k_{0}-1\right)=\log \left(K_{\mathrm{c}} / k_{0}\right)+n \log [\text { TEDA-Mn(acac })_{2}\right]
$$


plots of $\log \left(k / k_{0}-1\right)$ vs. $\log$ [TEDA-Mn(acac $\left.)_{2}\right]$ indicated a linear relation between $k$ and [TEDA$\left.\mathrm{Mn}(\mathrm{acac})_{2}\right]$. $k$ was proportional to 0.88 power of the TEDA-Mn(acac $)_{2}$ concentration. From these results, the $k$ is expressed as follows:

$$
k=k_{0}+K_{\mathrm{c}}\left[\mathrm{TEDA}-\mathrm{Mn}(\mathrm{acac})_{2}\right]^{0.88}
$$

In the case of only $\mathrm{Mn}(\mathrm{acac})_{2}, k$ was proportional to 1.00 power of the $\mathrm{Mn}(\mathrm{acac})_{2}$ concentration and this value was coincided with literature data. ${ }^{17}$ The 0.88 power observed here is lower than the 1.00 observed for the reaction catalyzed by $\mathrm{Mn}(\mathrm{acac})_{2}$. This suggests formation of a new complex by the HDI and TEDA coordination to $\mathrm{Mn}(\mathrm{acac})_{2}$.

To be clear structure of the resulting complex, FTIR spectrum (in $\mathrm{KBr}$ pellet) of the complex was studied at $4600-400 \mathrm{~cm}^{-1}$. The coordination of HDI and $\mathrm{Mn}(\mathrm{acac})_{2}$ was achieved via oxygen or nitrogen atoms in the NCO group. The nitrile in the NCO group, coordinates to the metal with an accompanying upward shift of $20-50 \mathrm{~cm}^{-1}$ of $\mathrm{CN}$ stretching frequency. ${ }^{18,19}$ The FT-IR spectrum of HDI-Mn(acac $)_{2}$ complex (HDI:Mn $(\mathrm{acac})_{2}=1: 1$ ) was found with appearance of the NCO peak at $2276 \mathrm{~cm}^{-1}$. The nitrile in the $\mathrm{NCO}$ group was involved in coordination with an upward shift of $25 \mathrm{~cm}^{-1}$ in $v_{\mathrm{CN}}$, and the FT-IR spectrum showed coordination of HDI to $\mathrm{Mn}(\mathrm{acac})_{2}$ via nitrogen atom in the NCO group. FT-IR spectrum of mixture of TEDA, HDI, and $\mathrm{Mn}(\mathrm{acac})_{2}$ was found with appearance of the NCO peak at $2270 \mathrm{~cm}^{-1}$. The relation between the NCO peak shift value and an affinity for complex was not clear, but TEDA will be coordinating HDI$\mathrm{Mn}(\mathrm{acac})_{2}$ complex.

Kinetics and FT-IR did not clearly indicate a mechanism for the TEDA/HDI-Mn(acac) $)_{2}$ catalytic system for the polyaddition reaction between HDI and DEG. The mechanism will be clarified by further investigation.
Acknowledgment. The authors are grateful to Tosho Co., Ltd. for providing the tertiary amines.

\section{REFERENCES}

1. A. Burkas and C. F. Eckert, J. Am. Chem. Soc., 80, 5948 (1958).

2. B. G. Alzner and K. C. Frisch, Ind. Eng. Chem., 51, 715 (1959).

3. A. Farkas and K. G. Flynn, J. Am. Chem. Soc., 82, 642 (1960).

4. F. Hostettler and E. F. Cox, Ind. Eng. Chem., 52, 609 (1960).

5. J. Burkus, J. Org. Chem., 26, 779 (1961).

6. I. Wakeshima and I. Kijima, Bull. Chem. Soc. Jpn., 48, 953 (1975).

7. E. P. Squiller and J. W. Rosthauser, Polym. Mater. Sci. Eng., 55, 640 (1986).

8. R. Lomölder, F. Plogmann, and P. Speier, J. Coat. Technol., 69, 51 (1997).

9. R. Lomoelder, F. Plogmann, and P. Speier, Paintindia, 48, 31 (1998).

10. K. K. Majumdar, A. Kundu, I. Das, and S. Roy, Appl. Organometal. Chem., 14, 79 (2000).

11. G. Anzuino, A. Pirro, O. Rossi, and L. Polo Friz, J. Polym. Sci., Polym. Chem. Ed., 13, 1657 (1975).

12. G. Anzuino, A. Pirro, O. Rossi, and L. Polo Friz, J. Polym. Sci., Polym. Chem. Ed., 13, 1667 (1975).

13. S. Dabi and A. Zilkna, Eur. Polym. J., 16, 475 (1979).

14. R. A. Ligabue, A. L. Monteiro, R. F. de Souza, and M. O. de Souza, J. Mol. Catal. A: Chem., 130, 101 (1998).

15. R. A. Ligabue, A. L. Monteiro, R. F. de Souza, and M. O. de Souza, J. Mol. Catal. A: Chem., 157, 73 (2000).

16. B. D. Nahlovsky and G. A. Zimmermun, Int. Jahrestag.Frannhofer - Inst. Treib - Explosivst. 18th. Technol. Energ. Mater., 39/1 (1987).

17. L. B. Weisfeld and P. G. Gemeinhart. J. Appl. Polym. Sci., 4, 207 (1960).

18. A. H. Norbury and A. I. P. Sinha, J. Chem. Soc., A, 1598 (1968).

19. J. Nelson and S. M. Nelson, J. Chem. Soc., A, 1597 (1969). 